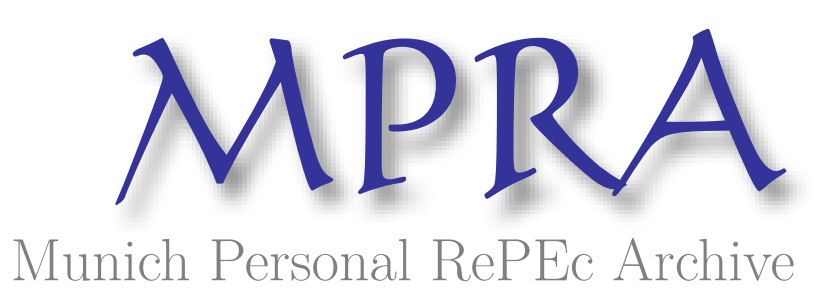

\title{
Extreme Weather Events and Migration: The Case of Morocco
}

Cong Nguyen, Minh and Wodon, Quentin

World Bank

June 2014

Online at https://mpra.ub.uni-muenchen.de/56938/

MPRA Paper No. 56938, posted 29 Jun 2014 13:46 UTC 


\title{
Extreme Weather Events and Migration: The Case of Morocco
}

\author{
Minh Cong Nguyen and Quentin Wodon
}

June 2014

This paper is forthcoming in:

Wodon, Q., A. Liverani, G. Joseph and N. Bougnoux, 2014 editors, Climate Change and Migration: Evidence from the Middle East and North Africa, Washington, DC: The World Bank.

\begin{abstract}
Do extreme weather events such as droughts or floods lead to migration away from the areas affected by these events? This chapter aims to provide an answer to that question for Morocco using a new nationally representative household survey implemented in 2009-10. The data suggest that around one in four households have been affected by weather shocks in the five years preceding the survey implementation. Droughts and floods are not directly identified by households as major reasons for migration, but insufficient agricultural revenue and a lack of agricultural employment as well as better employment opportunities at the place of destination are mentioned as reasons to migrate, and these are affected by adverse weather shocks. Furthermore, in regression analysis, after controlling for a wide range of individual and household characteristics, the probability of both temporary and permanent migration increases if the household has been affected by an adverse weather shock or the consequences thereof. Thus, while adverse weather events may not be the main driver of migration, they do contribute to it.
\end{abstract}




\section{Introduction}

The frequency of droughts has increased in Morocco over the last few decades, with negative impact on farmers and the economy as a whole (Azzam and Sekkat, 2005; Barakat and Handoufe, 1998; Skees, 2001). Most agricultural land is not irrigated, which means that affected households often have limited ways to reduce the impact of droughts on their livelihood (Skees, 2001; Swearingen and Bencherifa, 2000). In chapter 6 of this study, a recent national household survey for Morocco was used to document the extent to which Moroccan households, and especially those involved in agriculture, are confronted with extreme weather events such as droughts. The analysis suggested that most households working in agriculture were affected by weather shocks, often seriously. In the population as a whole, the proportion of households affected was about one fourth, simply because households not in agriculture were not likely to be affected. Many households affected declared not being able to recover from these shocks.

Given the high level of vulnerability of households to weather shocks and their limited means to cope with the shocks and adapt to climate change, one might expect that weather shocks would contribute to out-migration in the affected areas. It would make sense that some household members would leave the areas most affected by drought, and there is indeed some evidence to this effect. After a severe drought in 2007, two thirds of the illegal migrants arrested in Spain were from the farming and mining region of Khouribga (EACH-FOR, 2008). Another study by Hamza, El Faskaoui and Fermin (2009) found that environmental degradation was one of the reasons leading to past or intended migration. Yet these studies have been fairly localized and based on small samples, so that it is difficult to generalize from them - for example the study by Hamza, El Faskaoui and Fermin has a sample size of 30, so that it is unclear at the national level whether climate shocks are a major or relatively small factor affecting migration.

The objective of this chapter is to test whether these weather shocks indeed contribute to migration, both temporary and permanent, by using a broader sample (for a brief review of the literature which informs this chapter, see the introduction of chapter 2 by Wodon et al. (2014) and chapter 3 on the focus countries for this work by Burger et al. (2014a) in this study. The analysis is based on a nationally representative household survey-the Morocco Household and Youth Survey (MHYS) implemented between December 2009 and March 2010. Much of the questionnaire of that survey focuses on issues critical to youth, such as the obstacles they encounter on the labor market and for civic participation. But the questionnaire also included data on migration as well as on various shocks affecting households and their ability to cope with these shocks. One of the shocks is that of adverse weather events (such as droughts and floods). It is thus feasible using econometric techniques to assess whether households who were affected by extreme weather events experienced higher migration rates among their members after controlling for a range of other household and individual characteristics.

The chapter is organized as follows. Section 2 introduces the data used for the analysis. Section 3 provides basic statistics on the extent to which households are affected by weather and other shocks, and on the extent of both temporary and permanent migration among household members. Section 4 then provides the multivariate analysis of the correlates of temporary and permanent migration among household members. A brief conclusion follows.

\section{Data}

As was the case for chapter 6 of this study, this chapter is based on data from the Morocco Household and Youth Survey (MHYS) implemented in 2009-2010. The survey is nationally representative (even if it does not include the scarcely populated Western Sahara southern part of the country) and it includes data on 2,000 households (1,216 in urban areas and 
784 in rural areas). The survey was implemented with funding from the World Bank between December 2009 and March 2010. Much of the questionnaire focused on issues critical to youth, and especially the obstacles that they encounter on the labor market and for civic participation. Questions were also asked about young people's intentions to emigrate. Other more traditional modules deal with standard questions on household member demographics and education as well as employment information. The questionnaire also focused on various shocks affecting households and their ability to cope with these shocks, including weather shocks. In order to be able to use the survey for this work on migration in the MENA region, additional questions as well as more options within existing questions were added to the questionnaire on household perceptions regarding changes in climate, and whether this affected migration decisions.

Apart from a range of household and individual characteristics which are used as controls in the regression analysis, a few central questions are used for the analysis presented in this chapter. In section 6A about the incidence of shocks and household responses, households are asked whether since November 2004, the respondent or a member of the household experienced various shocks. The shocks listed are: (1) Weather shocks (Droughts; floods; Pest infestation, crop and livestock diseases); (2) Unexpected increase in prices of food or other essential commodities consumed; (3) Unexpected loss of job; (4) Involuntary reduction in employment or the number of hours worked; (5) Unexpected decline in prices or demand for products that you sell; (6) Unexpected increase in prices or shortages of inputs or products needed for your activity; (7) Loss of asset or of livestock due to theft, death, or accident; (8) Cut-off or decrease in remittances to household; (9) Death of main earner for the household; (10) Death of another member of the family; (11) Serious injury or illness that kept any member from doing normal activities; (12) Divorce or abandonment by husband; (13) Big amount of dowry for daughter's marriage; (14) Other (specify). This is the information used in the regression analysis to assess the impact of weather shocks on migration controlling for a range of other independent variables.

Data on migration is available for all household members, both those who remain today members of the households, and those who used to be members but have left permanently. We can thus measure both temporary and permanent migration by household members. On the other hand, we only record the migration of household members, as opposed to that of whole households, but this should not be too much of a problem given that most migration is typically undertaken by household members, instead of entire households. It must also be recognized that it is difficult to distinguish the separate effects of climate change, environmental change, and weather shocks on households, and to separate short-term versus long-term household responses. What the questionnaire provides us with is information on whether households declare having been affected by a weather shock - but the decision to migrate is probably based on repeated shocks or changing conditions, as opposed to a single shock, and we cannot verify to what extent the declarations of households correspond closely to actual weather data for their area. But on the other hand one could argue that decisions such as that of migrating are influenced at least as much by perceptions of households of weather patterns as by the weather patterns themselves.

While all households respond to the question of whether they suffered from a weather shocks, in a separate part of the questionnaire households working in agriculture are asked whether they were faced with a number problems in the last five years. The list of problems identified was as follows: (1) Reduction in agricultural yields due to inadequate rainfall (periodic and recurrent water scarcity due to droughts); (2) Reduction in agricultural yields due to too much water (too much rain or flooding); (3) Poor soil quality due to erosion reducing agricultural yields; (4) Changing and unpredictable climate and temperatures reducing agricultural yields (i.e. too hot, too cold, too rainy, too dry); (5) Pest or locust infestation reducing agricultural yields; 
(6) Reduced job opportunities in the agricultural sector; (7) Death of livestock due to bad weather conditions; (8) Reduction in the stock of livestock since the availability of grazing land is becoming less due to droughts and floods. Next households were asked: "How serious was the financial loss to the household due to these climate related factors listed above?" The potential answers were very serious, moderate, serious, and negligible. Finally households were asked "Was (the household) forced to change the economic activity after the shock?" This information will also be used in the regression analysis as some problems encountered by agricultural households - who tend to be more exposed to climate shocks - may lead to migration and the problems identified in the questionnaire may potentially better capture changes in structural environmental conditions than a weather shock would.

\section{Basic Statistics}

Table 1 provides summary statistics on the main variables of interest. The first two columns of the table give the migration rates observed for the various groups of households or individuals. The last two tables provide the summary statistics for the same variables as they are used in the regression analysis - note that in a number of cases the summary statistics are missing and replaced by the symbol "_" because these are the excluded reference categories in the regressions (the shares of those with that dummy variable can be readily computed from the other shares for the corresponding category of variables). In what follows, we focus the discussion of the basic statistics on the migration rates, while the summary statistics are provided simply for the sake of completeness in information and standard practice.

The temporary migration rate is at 5.71 percent for the sample as a whole, and is a bit higher than the permanent migration rate, at 4.00 percent. The temporary migration rate is at its highest level among individuals aged 25 to 34, while for permanent migration, the rate is highest among those aged 15 to 24 . The older an individual gets, the less likely it is that s/he will migrate. Migration rates are much higher for women than for men, and this is confirmed when looking at the position of the individual in terms of being a head of household or a spouse (rates for spouses are much higher), or at the interaction effects between gender and marital status. 


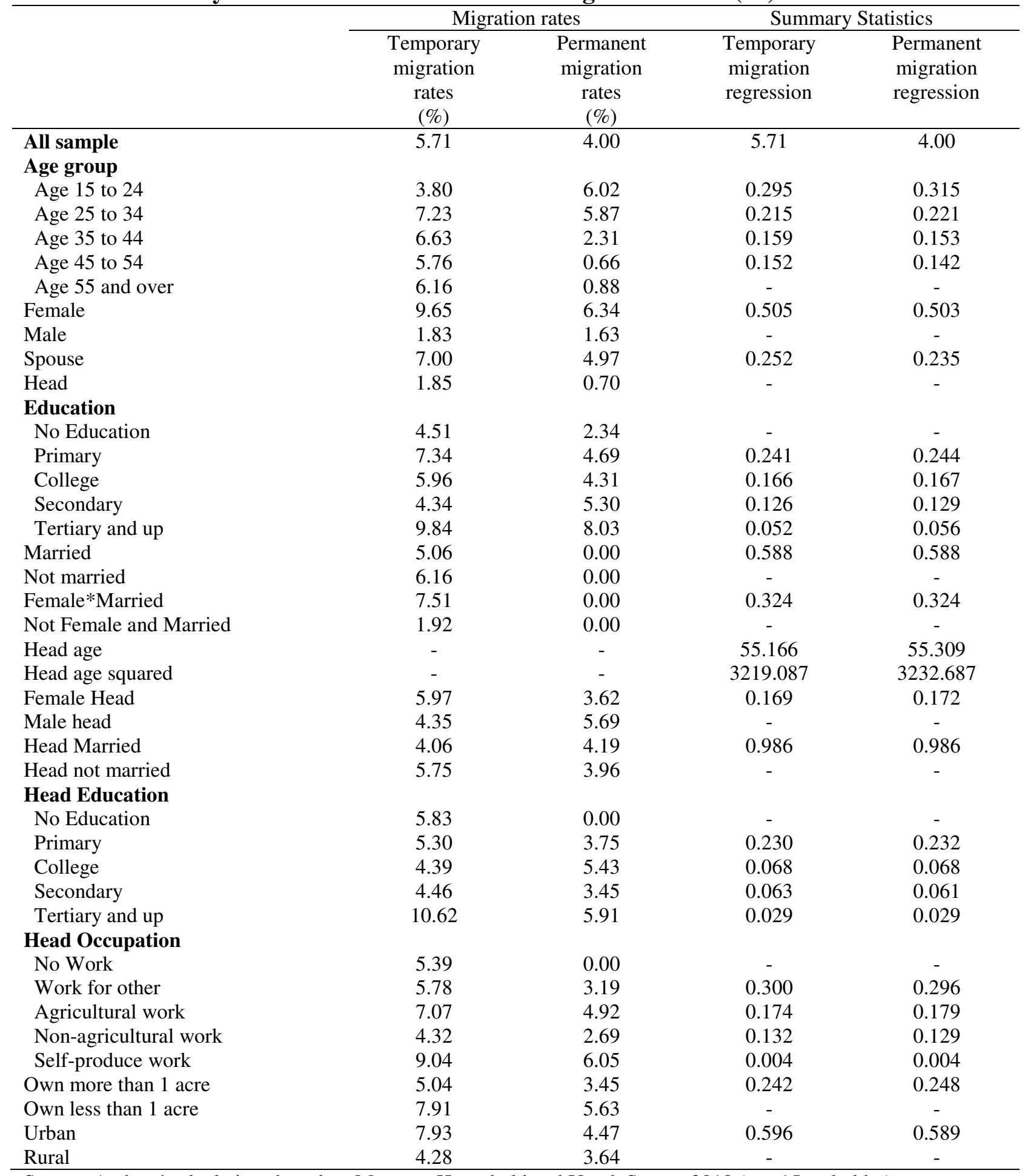

Source: Authors' calculations based on Morocco Household and Youth Survey 2010 (age 15 and older). Number of observations: 7884 for temporary migration, 8502 for permanent migration. 
Table 1 (cont.): Summary Statistics on Individual Level Migration Rates (\%)

\begin{tabular}{|c|c|c|c|c|}
\hline & \multicolumn{2}{|c|}{ Migration rates } & \multicolumn{2}{|c|}{ Summary Statistics } \\
\hline & $\begin{array}{l}\text { Temporary } \\
\text { migration } \\
\text { rates } \\
(\%)\end{array}$ & $\begin{array}{l}\text { Permanent } \\
\text { migration } \\
\text { rates } \\
(\%)\end{array}$ & $\begin{array}{l}\text { Temporary } \\
\text { migration } \\
\text { regression }\end{array}$ & $\begin{array}{l}\text { Permanent } \\
\text { migration } \\
\text { regression }\end{array}$ \\
\hline \multicolumn{5}{|l|}{ Wealth index } \\
\hline Q1 & 9.58 & 4.97 & - & - \\
\hline Q2 & 6.85 & 3.45 & 0.200 & 0.200 \\
\hline Q3 & 4.31 & 3.52 & 0.207 & 0.205 \\
\hline Q4 & 3.17 & 3.34 & 0.213 & 0.210 \\
\hline Q5 & 4.95 & 4.68 & 0.175 & 0.175 \\
\hline \multicolumn{5}{|l|}{ Regions } \\
\hline Guélmim-Es Semara & 2.73 & 5.15 & 0.024 & 0.024 \\
\hline Souss-Massa-Draâ & 12.56 & 5.68 & 0.106 & 0.107 \\
\hline Gharb-Cherarda-Béni Hssen & 6.65 & 2.65 & 0.071 & 0.069 \\
\hline Chaouia-Ouardigha & 6.79 & 4.23 & 0.078 & 0.079 \\
\hline Marrakech-Tensift-Al Haouz & 8.99 & 2.54 & 0.114 & 0.114 \\
\hline Oriental & 1.08 & 1.47 & 0.058 & 0.056 \\
\hline Grand-Casablanca & 2.28 & 3.44 & 0.131 & 0.130 \\
\hline Rabat-Salé-Zemmour-Zaér & 4.47 & 3.69 & 0.068 & 0.067 \\
\hline Doukala-Abda & 7.06 & 4.13 & 0.061 & 0.061 \\
\hline Tadla-Azilal & 5.52 & 7.67 & 0.061 & 0.064 \\
\hline Méknès-Tafilalet & 3.54 & 7.12 & 0.062 & 0.063 \\
\hline Fès-Boulemane & 1.81 & 1.98 & 0.045 & 0.045 \\
\hline Taza-Al Hoceima-Taounate & 7.83 & 3.00 & 0.078 & 0.078 \\
\hline Tanger-Tétouan & 1.47 & 3.09 & - & - \\
\hline \multicolumn{5}{|l|}{ Economic and climate shocks } \\
\hline Weather shocks (droughts, floods, etc.) & 4.82 & 3.79 & 0.248 & 0.252 \\
\hline No Weather shocks (droughts, floods, etc.) & 8.53 & 4.52 & - & - \\
\hline Unexpected increase in prices of food/other & 5.01 & 4.10 & 0.735 & 0.736 \\
\hline No Unexpected increase in prices & 5.96 & 3.92 & - & - \\
\hline Job related shocks & 5.26 & 4.13 & 0.249 & 0.249 \\
\hline No Job related shocks & 7.04 & 3.48 & - & - \\
\hline Cut-off or decrease in remittances & 5.62 & 3.80 & 0.015 & 0.017 \\
\hline No Cut-off or decrease in remittances & 11.65 & 14.21 & - & - \\
\hline Death/sick of HH member (incl. main earner) & 5.51 & 3.81 & 0.117 & 0.119 \\
\hline No Death/sick of HH member (incl. main earner) & 7.19 & 5.21 & - & - \\
\hline \multicolumn{5}{|l|}{ Climate change and shock in agriculture } \\
\hline Reduction in agricultural yield due to less water & 4.85 & 3.46 & 0.236 & 0.243 \\
\hline No Reduction in agricultural yield due to less water & 8.58 & 5.63 & - & - \\
\hline Reduction in agricultural yield due to more water & 5.54 & 3.70 & 0.169 & 0.173 \\
\hline No Reduction in agricultural yield due to more water & 6.56 & 5.32 & - & - \\
\hline Reduced job opportunities in the agricultural sector & 5.15 & 3.98 & 0.149 & 0.150 \\
\hline No Reduced job opportunities in the agricultural sector & 8.97 & 3.89 & - & - \\
\hline Serious financial loss due to climate related factors & 5.50 & 4.06 & 0.092 & 0.092 \\
\hline No Serious financial loss due to climate related factors & 7.79 & 3.09 & - & - \\
\hline Change the economic activity after the shock & 5.39 & 3.84 & 0.056 & 0.058 \\
\hline No Change the economic activity after the shock & 10.87 & 5.93 & - & - \\
\hline
\end{tabular}

Source: Authors' calculations based on Morocco Household and Youth Survey 2010 (age 15 and older).

Number of observations: 7884 for temporary migration, 8502 for permanent migration. 
In general, and especially in the case of permanent migration, migration rates are higher among the better educated. This is observed whether one looks at the education level of the individuals, or at that of the household heads. Migration rates also tend to be higher among households whose heads is self-employed, which would include small business owners. There are also higher among individuals belonging to a household with little hand, possibly because there is less pressure to stay at the place of origin in order to work the land. Temporary migration is especially high among poorer households as measured through an index of wealth, while permanent migration is slightly higher among both the bottom and the top quintiles.

Migration rates are higher among household located in urban areas, which may indicate substantial migration from smaller to larger areas as well as international migration from urban centers. There are also large differences in migration rates depending of the regions where households live. The highest temporary migration rate is observed in Souss-Massa-Draâ, followed by Marrakech-Tensift-Al Haouz, Taza-Al Hoceima-Taounate, Doukala-Abda, ChaouiaOuardigha, and Gharb-Cherarda-Béni Hssen. For permanent migration, the highest rates are observed from Tadla-Azilal, Méknès-Tafilalet, Souss-Massa-Draâ, and Guélmim-Es Semara.

When looking at migration rates according to whether households have been exposed to weather and other types of shocks, it is remarkable to note that migration rates are essentially always higher among households who were not affected by negative shocks. This does not mean that shocks, including weather shocks, may not be correlated with migration in a multivariate setting, but it does suggest that overall, in the country as a whole, much of the migration that is taking place may not be primarily related to weather shocks.

A similar message emerges from the data provided in table 2 on the reasons declared by households for the migration of household members. For temporary migration, the main motivation by far is the fact that better offers of agriculture employment are available at the place of destination - this is the rationale for half of all temporary migrants. The same reason is mentioned for permanent migration, although in that case marriage is mentioned more often. The lack of jobs at the place of origin is mentioned, and it could be related to adverse weather conditions. It could also be that the availability of better agricultural employment at the place of destination is related to the effect of climate change and droughts at the place of origin. But this cannot simply be assumed given that being a victim of a drought or a flood is explicitly listed among the potential reasons to migrate in the questionnaire, and that very few households declare that these were the main reasons for the migration decisions of their members. 
Table 2: Reasons for Migration by Household Members, Morocco 2009-10 (\%)

\begin{tabular}{lcc}
\hline & $\begin{array}{c}\text { Temporary } \\
\text { migration }\end{array}$ & $\begin{array}{c}\text { Permanent } \\
\text { migration }\end{array}$ \\
\hline Migration with the rest of the household & 6.97 & 1.21 \\
Better business opportunities in the new place & 3.70 & 2.57 \\
Low offer of jobs in the non-agriculture in place of origin & 9.57 & 4.53 \\
Change of profession & 6.25 & 2.94 \\
Studies of the person & 6.27 & 4.91 \\
Better infrastructure & 0.00 & 0.48 \\
Family reunification, join the large family & 6.53 & 3.16 \\
Marriage & 0.71 & 44.67 \\
Divorce separation & 0.20 & 1.29 \\
Victim of flood & 0.12 & 0.00 \\
Victim of drought & 0.53 & 0.40 \\
Victim of another environmental cause & 0.20 & 0.00 \\
Insufficient agricultural revenue or low agricultural employment & 5.31 & 1.09 \\
Better offers of agriculture employment in the new place & 49.37 & 27.45 \\
Other & 4.27 & 5.31 \\
Total & 100 & 100 \\
\hline
\end{tabular}

Source: Authors.

\section{Correlates of the Probability of Migration}

The basic statistics presented in the previous section appear to suggest that migration rates are lower in areas affected by extreme weather shocks. This does not mean however that weather shocks have a negative impact on migration. For example, a positive association was found between education and the likelihood of migration. If migration is lower among households affected by weather and other shocks, this might simply reflect the fact that these households tend to live in rural areas, work in agriculture, and be less well educated. Controlling for education, it could very well be that weather shocks could have a positive effect on migration. In order to assess the marginal impact of weather and other shocks on migration after controlling for a range of individual and household characteristics, this section provides a regression analysis of the likelihood of temporary and permanent migration in a multivariate setting. The analysis is still descriptive, but it enables us to assess whether controlling for individual and household characteristics as well as broad levels of geographic location, adverse weather shocks have a statistically significant effect on migration, whether positive or negative.

Table 3 provides the results of probit regressions (with robust standard errors) for the correlates of the probability of migrating either temporarily or permanently. Note that in the case of permanent migration, only migration for reasons not related to marriage is considered. Two different specifications for the model are provided - the second specification includes a series of additional household level variables which are not included in the first because of the risk of endogeneity with those variables in that, for example, migration may affect who is considered as the household head, or the education level of the household head. This risk of endogeneity is much larger in the case of permanent migration, but for comparison purposes the two models are estimated for both regressions. Marginal effects are provided $(\mathrm{dF} / \mathrm{dX})$, so that a value of 0.02 would represent an increase in the likelihood of migration of two percentage points.

The main variables of interest are at the bottom of table 3, and we start the discussion with those. Being subject to an adverse weather shock appears to increase the probability of temporary migration depending on the specification, but not the probability of permanent migration. It looks like household members are coping with weather shocks (which might be one-time events) by looking for work elsewhere, but that these conditions do not yet lead to 
permanent departures. However, a reduction in agricultural yields due to less water increases permanent migration, suggesting that when the changes in environmental conditions are perceived to be more permanent, some household members do feel the need to migrate permanently. By contrast, a reduction in agricultural yields due to excess water (probably through floods) reduces the likelihood of migrating temporarily, possibly because the shocks may reduce the resources available to household members to migrate, and such shocks are not as likely to be perceived as permanent changes in conditions that affect long-term livelihood.

Unexpected increases in prices of food and others basic commodities also lead to more temporary migration, but the effect is only marginally significant in one of the two specifications, so one could argue that there is no clear effect. Finally, the largest effect on both temporary and permanent migration comes from being affected by a cut-off or decrease in remittances from previous household members who had migrated. This decrease in remittances leads to a large increase in both types of migration, suggesting a certain level of dependence on remittances among the households receiving them since they send other members away when this is the case (note that the ability to send new members away may be facilitated by network effects that having other members who migrated before entail).

Apart from shocks, a number of individual level characteristics affect the probability of migration. Younger individuals are more likely to migrate permanently, given that they have often not yet created a household at the place of origin, but age does not affect the probability of temporary migration in the same way. Better educated individuals appear to be more likely to migrate temporarily, but not permanently. Those who are married are more likely to migrate temporarily, but this is essentially the case for men who are heads of households, while married head are less likely to migrate permanently. As to household level characteristics, temporary migration is more frequent among members for the poorest households (bottom quintile of wealth), but the differences are less systematic for permanent migration. Whether households own more than one acre of land or not does not make much difference after controlling for other variables. Households where the head does not have work are more likely to have temporary migrants.

While the urban versus rural location of the household does not have a statistically significant impact on the probability to migrate, there are geographic effects at work after controlling for individual and household characteristics. The reference geographic location in the regression model is the prefecture of Tanger-Tétouhan, which is located in the tip of the northern part of the country towards Spain. In comparison to that region, temporary migration is lower in Oriental, Grand-Casablanca, Méknès-Tafilalet, and Fès-Boulemane, and higher in Souss-MassaDraâ. Again in comparison to Tanger-Tétouhan, permanent migration is lower in ChaouiaOuardigha, Marrakech-Tensift-Al Haouz, and Fès-Boulemane, and higher in Tadla-Azilal. 
Table 3: Correlates of Individual Migration, Morocco 2009-10 (dF/dX)

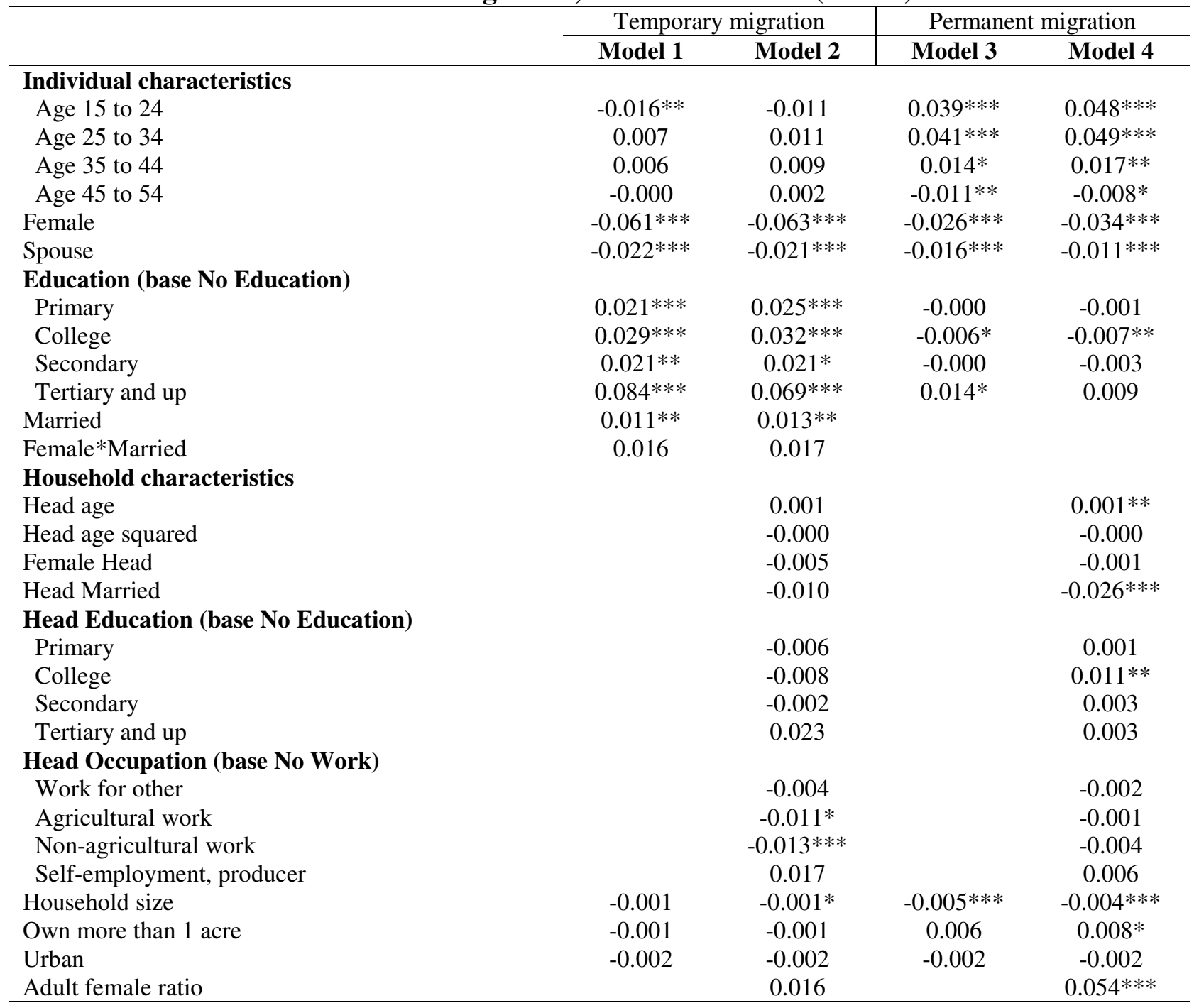

Source: Authors' calculations based on Morocco Household and Youth Survey 2010.

Note: ${ }^{* * *} \mathrm{p}<0.01, * * \mathrm{p}<0.05,{ }^{*} \mathrm{p}<0.1$. Region dummies are included but not reported here. 
Table 3 (continued): Correlates of Individual Migration, Morocco 2009-10 (dF/dX)

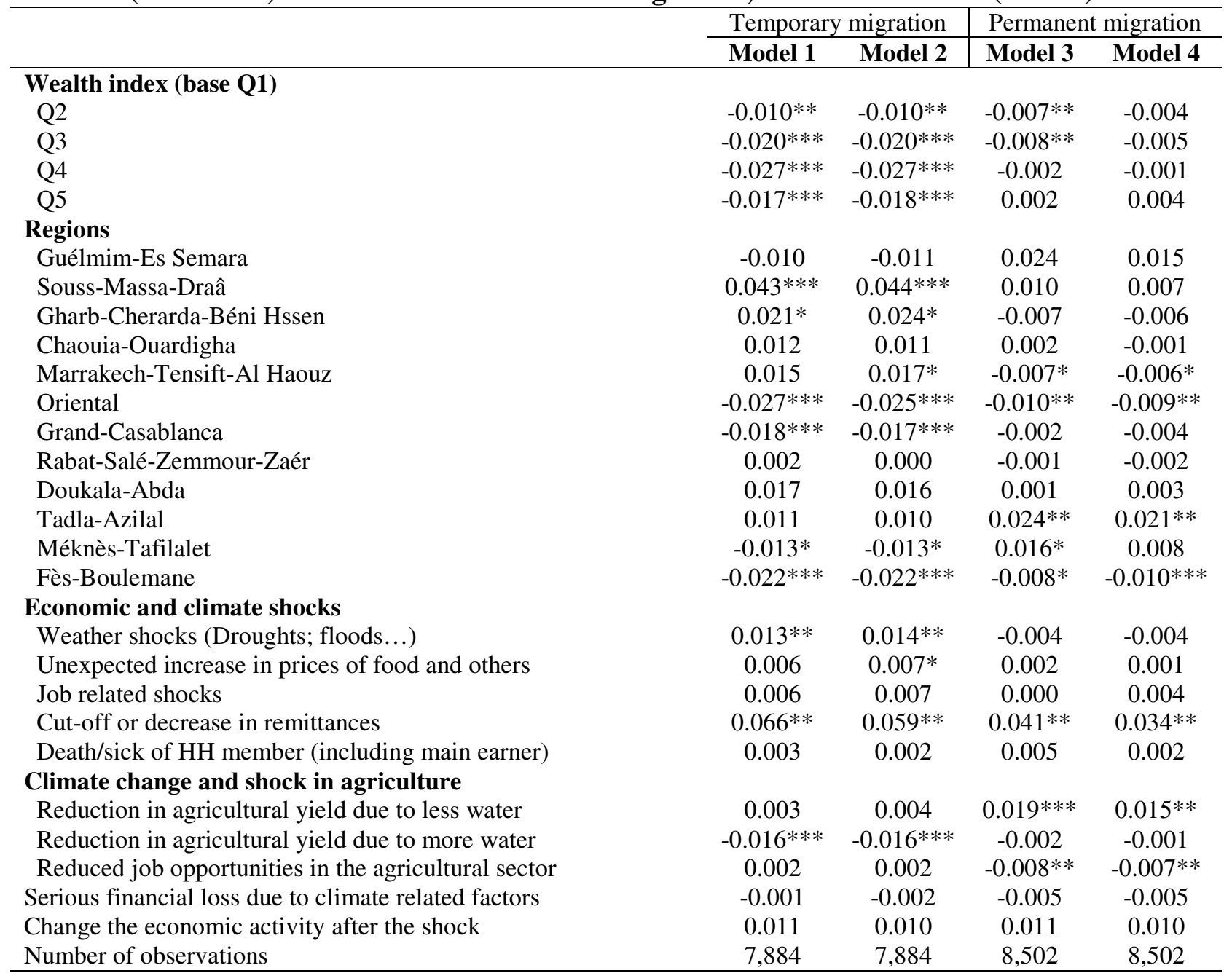

Source: Authors' calculations based on Morocco Household and Youth Survey 2010.

Note: $* * * \mathrm{p}<0.01, * * \mathrm{p}<0.05, * \mathrm{p}<0.1$. Region dummies are included but not reported here.

\section{Conclusion}

Do extreme weather events such as droughts or floods lead to migration away from the areas affected by these events in Morocco? The analysis presented in this chapter suggests that this is the case. While droughts and floods are not directly identified by households as major reasons for migration, the characteristics of areas affected by droughts, such as insufficient agricultural revenue and employment are mentioned as reasons for migration by households. Furthermore, in regression analysis, being subject to an adverse weather shock appears to increase the probability of temporary migration, and a reduction in agricultural yields due to less water (droughts) increases permanent migration. Other factors do have a larger effect on the probability of migration, so that climate and environment related variables may not be the main drivers of temporary and permanent migration. But they do appear to contribute to migration. 


\section{References}

Azzam, A., and K. Sekkat, 2005. "Measuring Total-Factor Agricultural Productivity under Drought Conditions: The Case of Morocco", The Journal of North African Studies 10(1): 19-31.

Barakat, F., and A. Handoufe, 1998. "Approche agroclimatique de la sécheresse agricole au Maroc", Sécheresse, 9: 201-208.

Burger, N., A. Grant, S. Kups, Y. Rana, and Q. Wodon, 2014, Focus Countries, in Q. Wodon, A. Liverani, G. Joseph, and N. Bougnoux, editors, Climate Change and Migration: Evidence from the Middle East and North Africa, World Bank Study, Washington, DC.

Elasha, B. O., 2010. "Mapping of Climate Change Threats and Human Development Impacts in the Arab Region," mimeo, New York: United Nations Development Program.

Foresight, 2011. Migration and Global Environmental Change, London: The Government Office for Science.

IPCC, 2012, Managing the Risks of Extreme Events and Disasters to Advance Climate Change Adaptation, in C. B. Field, V. Barros, T. F. Stocker, D. Qin, D. J. Dokken, K. L. Ebi, M. D. Mastrandrea, and G.-K. P. K.J. Mach, S.K. Allen, M. Tignor, and P.M. Midgley, Eds., A Special Report of Working Groups I and II of the Intergovernmental Panel on Climate Change, Cambridge University Press, Cambridge, UK, and New York, NY, USA.

McSweeney, C., M. New, and G. Lizcano, 2009. UNDP Climate Change Profiles: Documentation, mimeo, New York: United Nations Development Program.

Skees, J., et al., 2001. "Developing Rainfall-Based index Insurance in Morocco", World Bank Policy Research Working Paper 2577, World Bank, Washington, DC.

Swearingen, W. D., and A. Bencherifa, 2000. "An Assessment of the Drought Hazard in Morocco", in D. A. Wilhite, Editor, Drought: A Global Assessment, Vol. 1, New York: Routledge.

Sowers, J., and E. Weinthal, 2010. Climate Change Adaptation in the Middle East and North Africa: Challenges and Opportunities, The Dubai Initiative Working Paper No. 2.

United Nations Development Programme and Arab Fund for Economic and Social Development. 2009. Arab Human Development Report 2009: Challenges to Human Security in the Arab Countries. New York: UNDP.

Verner, D., Editor, 2012, Adaptation to a Changing Climate in the Arab Countries, Directions in Development, World Bank, Washington, DC.

Warren, R., N. Nicholls, R. Levy, P. Price, J. 2006. "Understanding the Regional Impacts of Climate Change: Research Report Prepared for the Stern Review on the Economics of Climate Change", Tyndall Centre for Climate Change, Research Working Paper 90.

Wodon, Q, N. Burger, A. Grant, and A. Liverani, 2014, Climate Change, Migration, and Adaptation in the MENA Region, in Q. Wodon, A. Liverani, G. Joseph, and N. Bougnoux, editors, Climate Change and Migration: Evidence from the Middle East and North Africa, World Bank Study, Washington, DC.

World Bank, 2007. World Bank Development Report 2008. Agriculture for Development, World Washington, DC: The World Bank.

World Bank, 2010, World Development Report 2010: Development and Climate Change, Washington, DC: World Bank. 